\title{
Birth preparedness and complication readiness among pregnant women in a rural community in southern Nigeria
}

\author{
S H Ibadin, MBBS; V Y Adam, MBBS, MPH, MWACP, FMCPH; O A Adeleye, MBBS, MPH, FWACP; \\ O H Okojie, MBBS, FWACP, FMCPH
}

Department of Community Health, University of Benin Teaching Hospital, Benin City, Nigeria

Corresponding author: S H Ibadin (serbalogun@gmail.com)

\begin{abstract}
Background. Birth preparedness and complication readiness (BPACR) has been advocated as a strategy to overcome costly delays in decision-making to seek skilled attendance at delivery, which in turn contribute significantly to maternal mortality from obstetric causes.

Objective. To assess the determinants of BPACR among pregnant women in a rural community in Edo State, Nigeria.

Methods. A descriptive cross-sectional study was done in Anegbette, a rural community in Etsako Central Local Government Area of Edo State. A house-to-house survey was carried out to identify pregnant women and all eligible women in the study area were included in the study.

Results. A total of 277 pregnant women participated in the study. The mean age (standard deviation) of respondents was 28.7 (5.8) years. Less than half $(134,48.4 \%)$ of the respondents were well prepared while $143(51.6 \%)$ were poorly prepared. After adjustment for confounding effect using binary logistic regression analysis, educational level (odds ratio (OR) 0.653, 95\% confidence interval (CI) 0.330 - 0.956), occupation (OR $0.384,95 \%$ CI 0.148 - 0.990) and utilisation of antenatal care (OR 3.407, 95\% CI 1.830 - 5.074) were significant predictors of BPACR.

Conclusion. BPACR was poor among women in the rural community. In order to improve maternal health among rural women in Nigeria, government and donor agency funding for safe motherhood programmes should focus on female empowerment and encourage community participation towards promotion of maternal health.
\end{abstract}

S Afr J Obstet Gynaecol 2016;22(2):47-51. DOI:10.7196/SAJOG.2016.v22i2.1088

Birth preparedness and complication readiness (BPACR) has been advocated as a strategy to overcome costly delays in decision-making to seek skilled attendance at delivery, which in turn contribute significantly to maternal mortality from obstetric causes. ${ }^{[1]}$ BPACR entails identifying a skilled provider and a birth location, learning to recognise the danger signs that may indicate life-threatening complications for the mother and baby, saving money and arranging for transportation, identifying a blood donor, identifying the nearest emergency obstetric services should pregnant women, their families and communities need to seek assistance in case of emergencies. ${ }^{[2]}$ In addition, BPACR requires health providers and facilities to be prepared to attend births and treat complications. ${ }^{[2]}$

BPACR among pregnant women is significantly influenced by their socioeconomic characteristics, among other personal factors. A study conducted among women attending antenatal care in south eastern Nigeria found that although $70.6 \%$ of women were aware of BPACR, knowledge of key danger signs in pregnancy was low; educational status was identified to be the best predictor of BPACR ${ }^{[3]}$ Similarly, having a higher education, upper socioeconomic status and being married were identified as factors associated with good BPACR among women receiving antenatal care in Benin City ${ }^{[4]}$ and Ile-Ife, ${ }^{[5]}$ Nigeria. A community-based survey in northern Nigeria among 5083 rural women recruited from three states found that BPACR practices were generally poor, with $33.2 \%$ having made no preparation for delivery; fewer than $2.5 \%$ had made provisions for a trip to the health facility at delivery and only $32.0 \%$ knew any critical danger sign relating to pregnancy and delivery. ${ }^{[6]}$
Most BPACR studies in southern Nigeria have been carried out among antenatal clinic attendees and may not necessarily provide a true representation of the actual BPACR practices of women living in rural communities where antenatal clinic attendance is suboptimal. Community-based surveys that reflect the BPACR practices of rural women appear to be lacking. Studying BPACR among rural women is necessary in order to highlight barriers that may impede good BPACR practices and provide a basis for specific interventions targeted at increasing utilisation of skilled birth attendants and improving maternal outcomes in rural communities.

This study assessed the determinants of BPACR among pregnant women in a rural community in Edo State, Nigeria.

\section{Methods \\ Study setting}

This study was conducted in Anegbette, a rural community in Etsako Central Local Government Area (LGA) of Edo State, Nigeria. Anegbette had a total population of 8 180, of whom 1799 women were of child-bearing age, in $2011 .{ }^{[7]}$ The community has a functional primary healthcare centre and is also served by a comprehensive health centre in a nearby town, Ekperi, and a general hospital located in the LGA headquarters, Fugar.

\section{Study design and selection of subjects}

A descriptive cross-sectional study was carried out. The study population consisted of all consenting pregnant women who were permanent residents of Anegbette. A minimum sample size of 170 
was calculated using a prevalence of $87.4 \%$ (the proportion of women with good BPACR from a similar study carried out in Edo State, Nigeria), ${ }^{[4]}$ standard normal deviation of 1.96 at $95 \%$ confidence level and power set at $80 \%$. A house-to-house survey was carried out to identify pregnant women and all eligible women in the study area were included in the study.

\section{Measures and data management}

A structured questionnaire was designed in line with the study objectives and administered by trained interviewers to pregnant women in their homes. The questionnaire was used to collect information on sociodemographic characteristics (age, educational level, marital status, religion, and occupation), utilisation of antenatal care (ANC) and BPACR practices. Utilisation of antenatal clinics was assessed solely by self-reporting. BPACR was assessed using questions adapted from the JHIPEGO BPACR matrix. ${ }^{[2]}$ Good knowledge of danger signs in pregnancy and labour was assessed by the respondents' awareness of at least three of the six symptoms in the matrix, namely: bleeding, liquor drainage before term, foulsmelling vaginal discharge, severe abdominal pain before term, headaches and fits. These symptoms signal potential complications of pregnancy. Women who met at least four of the eight BPACR criteria, which include: good knowledge of danger signs, saving money towards delivery, purchased items for the baby, identified a health facility for delivery, arranged for accompaniment in case of emergencies, made plans for transportation, identified a blood donor or blood bank, and identified the nearest facility for emergency obstetric care, were classified as being well prepared.

Data were analysed using IBM SPSS version 20.0 software (IBM, USA). Sociodemographic characteristics and utilisation of ANC were the independent variables and the main outcome measure was BPACR. Chi-squared test was used to determine the significance of associations between the independent variables and BPACR. All variables were included in a binary logistic regression model to determine their independent effects. Odds ratios (ORs) and their respective $95 \%$ confidence intervals (CIs) were obtained. Statistical significance was set at $p<0.05$.

\section{Ethical consideration}

Permission to carry out the study was granted by the chairman of Etsako Central LGA and the village head of Anegbette community. Verbal informed consent to participate in the study was obtained from each respondent. At the end of the interview, the participants were health educated on BPACR and the need to utilise maternal health services, especially skilled birth attendants.

\section{Limitation}

The terms 'good knowledge' and 'well prepared' as used to express the authors' assessment of knowledge of danger signs in pregnancy and BPACR practices are discretionary because of lack of uniform standards. The meaning of these terms may therefore vary significantly from previous usage in other similar literature.

\section{Results \\ Sociodemographic characteristics}

A total of 277 pregnant women participated in the study. The sociodemographic characteristics of the respondents are shown in Table 1. The age of respondents ranged from 17 to 46 years, with a mean age (standard deviation (SD)) of 28.7 (5.8) years. Over three- quarters $(232,83.7 \%)$, of the women were aged between 15 and 34 years, and 260 (93.9\%) were married. Among the participants, 118 (42.6\%) had no formal education while 116 (41.9\%), 41 $(14.8 \%)$ and $2(0.7 \%)$ had attained primary, secondary and tertiary education, respectively. Most $(228,82.3 \%)$ of the women were unskilled workers, $247(89.2 \%)$ were Etsako (the predominant ethnic group), and 224 (80.9\%) were Christians (the most practised religion).

\section{Birth preparedness and complication readiness}

As shown in Table 2, 134 (48.4\%) pregnant women were well prepared while 143 (51.6\%) were poorly prepared. More than half the respondents were saving money for delivery (158 (57.0\%)); 147 $(49.5 \%)$ had identified a health facility and skilled birth attendants for delivery, 135 (48.7\%) had arranged for accompaniment in case of emergencies and 95 (34.3\%) had made arrangements for transportation. Identification of blood donors or blood banks and facilities for emergency obstetric care was poor, with less than $15 \%$ of respondents having carried out these actions.

Knowledge of danger signs in pregnancy was relatively high, with $173(62.5 \%)$ of women knowing at least three symptoms that signal

Table 1. Sociodemographic characteristics of respondents $(N=277)$

\begin{tabular}{|c|c|c|}
\hline Variables & Categories & $n(\%)$ \\
\hline \multirow[t]{4}{*}{ Age (years) } & $15-24$ & $75(27.1)$ \\
\hline & $25-34$ & $157(56.7)$ \\
\hline & $35-44$ & $42(15.2)$ \\
\hline & $45-49$ & $3(1.1)$ \\
\hline \multirow[t]{4}{*}{ Educational level } & No formal education & $118(42.6)$ \\
\hline & Primary & $116(41.9)$ \\
\hline & Secondary & $41(14.8)$ \\
\hline & Tertiary & $2(0.7)$ \\
\hline \multirow[t]{4}{*}{ Marital status } & Single & $6(2.2)$ \\
\hline & Married & $260(93.9)$ \\
\hline & Divorced & $3(1.1)$ \\
\hline & Cohabiting & $8(2.9)$ \\
\hline \multirow[t]{4}{*}{ Occupational classification } & Unemployed & $22(7.9)$ \\
\hline & Unskilled & $228(82.3)$ \\
\hline & Semi-skilled & $2(0.7)$ \\
\hline & Skilled & $25(9.0)$ \\
\hline \multirow[t]{3}{*}{ Religion } & Christianity & $224(80.9)$ \\
\hline & Islam & $48(17.3)$ \\
\hline & ATR & $5(1.8)$ \\
\hline \multirow[t]{3}{*}{ Ethnicity } & Etsako & $247(89.2)$ \\
\hline & Esan & $14(5.1)$ \\
\hline & Others* & $16(5.7)$ \\
\hline $\begin{array}{l}\text { ATR = African traditional religion. } \\
{ }^{*} \text { Others include Benin, Esan, Fulani, }\end{array}$ & nd ljaw. & \\
\hline
\end{tabular}


potential complications; however, 59 (21.3\%) of the women did not know any danger signs (Table 3 ). The most frequently recognised symptoms among all respondents were: bleeding 173 (62.5\%), liquor drainage before term $167(60.3 \%)$ and abdominal pain before term 166 (59.9\%). Only $86(31.0 \%)$ knew that severe headache was a danger sign in pregnancy.

A total of 165 (59.6\%) of women had registered for ANC at a health facility at the time of the study.

BPACR was significantly associated with educational level $\left(\chi^{2}=\right.$ 7.262, $p=0.007)$ and occupation $\left(\chi^{2}=7.911, p=0.005\right)$; with BPACR being better among women who had attained at least primary education $(54.1 \%)$ and women who were semi-skilled or skilled workers $(74.1 \%)$, as compared with those who had no formal education (32.2\%) and were unskilled or unemployed (45.6\%). A higher proportion of women who had registered for ANC were well prepared (61.8\%) as against women who were unbooked $(28.6 \%)$; this association was also statistically significant $\left(\chi^{2}=29.528\right.$, $p<0.001)$. Women who were married also had better BPACR practices than unmarried and separated women; however, this association was not statistically significant (Table 4).

Table 2. Birth preparedness and complication readiness among respondents $(N=277)$

\begin{tabular}{ll}
\hline BPACR criteria & $\boldsymbol{n}(\mathbf{\%})^{*}$ \\
\hline Had good knowledge of danger signs & $173(62.5)$ \\
Saving money towards delivery & $158(57.0)$ \\
Purchased items for the baby & $147(53.1)$ \\
Identified a health facility for delivery & $137(49.5)$ \\
Arranged for accompaniment in case of emergencies ${ }^{\dagger}$ & $135(48.7)$ \\
Made plans for transportation & $95(34.3)$ \\
Identified blood donor or blood bank & $34(12.3)$ \\
Identified nearest facility for EmOC ${ }^{\ddagger}$ & $30(10.8)$ \\
Well prepared & $134(48.4)$ \\
Poorly prepared & $143(51.6)$ \\
${ }^{*}$ Multiple responses allowed. & \\
${ }^{*}$ Among the 135 women who had arranged for accompaniment, $127(94.1 \%)$ reported that their \\
${ }^{*}$ Emergency obstetric care.
\end{tabular}

Table 3. Knowledge of danger signs that may signal complications among respondents $(N=277)$

\begin{tabular}{ll}
\hline Variable & $\boldsymbol{n}(\%)^{*}$ \\
\hline Knowledge of symptoms & $187(67.5)$ \\
Bleeding & $167(60.3)$ \\
Liquor drainage before term & $166(59.9)$ \\
Abdominal pain before term & $156(56.3)$ \\
Fits & $139(50.2)$ \\
Foul-smelling vaginal discharge & $86(31.0)$ \\
Severe headaches & \\
Overall knowledge & $173(62.5)$ \\
Good knowledge & $104(37.5)$ \\
Poor knowledge & \\
${ }^{\dagger}$ Multiple responses allowed. &
\end{tabular}

After adjustment for confounding effect using binary logistic regression analysis, educational level (OR $0.653,95 \%$ CI 0.330 - 0.956), occupation (OR 0.384, 95\% CI 0.148 - 0.990) and utilisation of ANC (OR 3.407, 95\% CI 1.830 - 5.074) were significant predictors of BPACR, with women who had no formal education or skills being less likely to be well prepared and women who had registered for ANC being more likely to be well prepared (Table 5).

\section{Discussion}

This study revealed that approximately two-thirds of the study population had good knowledge of key danger signs in pregnancy, while one-fifth had no knowledge of danger signs. Although bleeding was the most frequently mentioned sign, less than $10 \%$ of women had identified potential blood donors/blood bank services or a facility where they could readily receive emergency obstetric care. In northern Nigeria, ${ }^{\left[{ }^{[6]}\right.}$ Ethiopia $^{[8]}$ and Uganda ${ }^{[9]}$ researchers also found that a significant proportion of rural women did not have adequate knowledge of signs that may signal complications and the majority of pregnant women failed to take the aforementioned BPACR actions. This suggests that many pregnant women may not understand the implications or severity of these symptoms, should they occur, or the extent to which they need to make advance preparations to avoid delays that may arise if they need special care during pregnancy and delivery.

Furthermore, over half the pregnant women in Anegbette community had poor BPACR. In contrast, another study among antenatal clinic attendees in Edo State found that the majority of the women interviewed (87.4\%) were well prepared. ${ }^{[4]}$ This discrepancy may be accounted for by the difference in the study population. Data from this study also suggest that BPACR practices in Anegbette were remarkably better than those observed among rural women in northern Nigeria, where less than $2.5 \%$ of those surveyed had made any provision for a trip to the health facility, saved money or made transport arrangements, compared with at least $34.3 \%$ of women in this study. ${ }^{[6]}$ BPACR practices have also been documented to be poor among rural women in Ethiopia ${ }^{[8]}$ and Tanzania. ${ }^{[10]}$ Poor BPACR has the potential to negatively influence the maternal and child health outcomes, as women who are not well prepared are less likely to utilise skilled birth attendants at delivery or respond to complications in an appropriate or timely manner.

Utilisation of ANC was found to be a significant determinant of BPACR. This may be as a result of the inclusion of BPACR messages in routine service delivery by skilled providers, and underscores the need for the improvement of antenatal coverage in rural communities. It was also observed that women who were uneducated or unskilled were disadvantaged compared with their counterparts who had attained at least primary education or were engaged in occupations requiring some level of skill. This observation is in consonance with findings of similar studies carried out in $\mathrm{Edo}^{[4]}$ and Osun $^{[5]}$ states in Nigeria, where educational level was also found to be significantly associated with BPACR. The role of education in the improvement of maternal outcomes has been well documented globally. Female education and empowerment have been proven to positively influence women to become more knowledgeable about their reproductive health, improve their decision-making capabilities, engage in beneficial health practices and increase utilisation of maternal health services. ${ }^{[1]}$ Providing educational and skill acquisition opportunities for rural women is thus imperative in order to improve BPACR and promote utilisation of skilled attendants at every delivery. 
RESEARCH

Table 4. Birth preparedness and complication readiness by sociodemographic characteristics and utilisation of antenatal care

\begin{tabular}{|c|c|c|c|c|c|}
\hline \multirow[b]{2}{*}{ Variables } & \multicolumn{3}{|c|}{ BPCR } & \multirow[b]{2}{*}{$\chi^{2}$} & \multirow[b]{2}{*}{$p$-value } \\
\hline & $\begin{array}{l}\text { Well prepared }(n=124) \text {, } \\
n(\%)\end{array}$ & $\begin{array}{l}\text { Poorly prepared }(n=153), \\
n(\%)\end{array}$ & $\begin{array}{l}\text { Total }(N=277), \\
n(\%)\end{array}$ & & \\
\hline \multicolumn{6}{|l|}{ Age } \\
\hline $15-34$ & $109(47.0)$ & $123(53.0)$ & $232(83.7)$ & 1.109 & 0.292 \\
\hline 35 and above & $25(44.4)$ & $20(55.6)$ & $45(16.3)$ & & \\
\hline \multicolumn{6}{|l|}{ Educational level } \\
\hline No formal education & $46(39.0)$ & $72(61.0)$ & $118(42.6)$ & 7.262 & 0.007 \\
\hline At least primary education & $88(55.3)$ & $71(44.7)$ & $159(57.4)$ & & \\
\hline \multicolumn{6}{|l|}{ Occupational classification } \\
\hline Unemployed and unskilled & $114(45.6)$ & $136(54 . .4)$ & $250(90.3)$ & 7.911 & 0.005 \\
\hline Semi-skilled and skilled & $20(74.1)$ & $7(25.9)$ & $27(9.7)$ & & \\
\hline \multicolumn{6}{|l|}{ Marital status } \\
\hline Married & $129(49.6)$ & $131(50.4)$ & $260(93.9)$ & 2.608 & 0.106 \\
\hline Not married/Separated & $5(29.4)$ & $12(70.6)$ & $17(6.1)$ & & \\
\hline \multicolumn{6}{|l|}{ Religion } \\
\hline Christianity & $116(51.8)$ & $108(48.2)$ & $224(80.9)$ & 5.452 & 0.020 \\
\hline Others & $18(34.0)$ & $35(66.0)$ & $53(19.1)$ & & \\
\hline \multicolumn{6}{|l|}{ Registered for ANC } \\
\hline Yes & $102(61.8)$ & $63(38.2)$ & $165(59.6)$ & 29.528 & $<0.001$ \\
\hline No & $32(28.6)$ & $80(71.4)$ & $139(40.4)$ & & \\
\hline
\end{tabular}

Although marital status was not significantly associated with BPACR, married women were observed to have better practices than unmarried or separated women. Spousal support may have contributed to this finding as the majority of the women reported that they would be accompanied by their husbands if they had an emergency. While this response does not necessarily reflect a high level of male participation, it does imply that married women receive additional support as compared with single respondents. Studies in Edo State ${ }^{[12,13]}$ and Northern Nigeria ${ }^{[14]}$ have however highlighted that male participation in maternal health issues is undesirably low and requires improvement. This highlights an opportunity that exists for improving BPACR and maternal health in rural communities through the education of men on their role in safe motherhood.

In addition to spousal and family support, the community also has a crucial part to play in ensuring pregnant women are well prepared and ready for any complications that may occur as BPACR is a shared responsibility. The majority of women in this study population were unaware of any community support mechanism/programme for pregnant women. This indicates that Anegbette community may not have an organised support system to cater for the special needs of pregnant women. This phenomenon was equally observed in other studies conducted in Edo State ${ }^{[4,12]}$ and suggests that community participation towards improving maternal health has been overlooked. Lack of community participation is likely to hinder improvements in safe motherhood, especially in resource-poor countries like Nigeria
Table 5. Predictors of birth preparedness and complication readiness

\begin{tabular}{|c|c|c|c|}
\hline Variables & OR & 95\% CI & $p$-value \\
\hline \multicolumn{4}{|l|}{ Age } \\
\hline $15-34$ & 1.104 & $0.968-1.063$ & 0.548 \\
\hline 35 and above & Reference & & \\
\hline \multicolumn{4}{|l|}{ Educational level } \\
\hline No formal education & 0.561 & $0.330-0.956$ & 0.033 \\
\hline At least primary education & Reference & & \\
\hline \multicolumn{4}{|l|}{ Social class by occupation } \\
\hline Unemployed/unskilled & 0.378 & $0.144-0.990$ & 0.048 \\
\hline Semi-skilled/skilled & Reference & & \\
\hline \multicolumn{4}{|l|}{ Marital status } \\
\hline Married & 1.558 & $0.501-4.844$ & 0.443 \\
\hline Not married/separated & Reference & & \\
\hline \multicolumn{4}{|l|}{ Religion } \\
\hline Christianity & 1.720 & $0.867-3.412$ & 0.121 \\
\hline Others & Reference & & \\
\hline \multicolumn{4}{|l|}{ Registered for ANC } \\
\hline Yes & 3.599 & $2.109-6.144$ & $<0.001$ \\
\hline No & Reference & & \\
\hline
\end{tabular}


where women are often socially and economically disadvantaged. Community participation plays a key role in health promotion, has been instrumental in bringing about appreciable gains in maternal health indices among poor people living in rural areas in India, Nepal and Bangladesh, ${ }^{[15]}$ and may be an effective way of improving BPACR and utilisation of skilled birth attendants among rural women in Nigeria.

\section{Conclusion}

This study found that BPACR was poor among women in Anegbette community. Educational level, occupation and utilisation of antenatal clinics were the determinants of BPACR

In order to improve maternal health among rural women in Nigeria, government and donor agency funding for safe motherhood programmes should be geared towards capacity building at the local level by encouraging the formation of community support groups and co-operative societies to educate and empower rural women economically and encourage utilisation of maternal health services. Maternal health campaigns in Nigeria should also focus on the participatory role of the community as a whole in ensuring safe motherhood.

Acknowledgement. The authors are grateful to the people of Anegbette community and also wish to express appreciation to the final-year medical students who assisted with data collection.

\section{References}

1. World Health Organization. Birth and Emergency Preparedness in Antenatal Care: Integrated Management of Pregnancy and Childbirth. Geneva: WHO Department of Making Pregnancy Safer 2006. http://www.who.int/reproductivehealth/publications/maternal_perinatal_health/emerggency preparedness_antenatal_care.pdf (accessed 24 April 2015).

2. Maternal and Neonatal Health (MNH) Program. Birth Preparedness and Complication Readiness: A Matrix of Shared Responsibilities. Baltimore, MD: MNH Program, 2001;1 - 7.

3. Ekabua JE, Ekabua KJ, Odusola P, Agan TU, Iklaki CU, Etokidem AJ. Awareness of birth preparednes and complication readiness in South Eastern Nigeria. ISRN Obstet Gynaecol 2011;el-6. http://dx.doi. org/10.5402/2011/560641

4. Tobin EA, Ofili AN, Nkemka E, Enueze O. Assessment of birth preparedness and complication readiness among women attending primary health care centres in Edo State, Nigeria. Ann Nigerian Med 2014;8:7681. http://dx.doi.org/10.4103/0331-3131.153358

5. Abioye Kuteyi EA, Kuku JO, Lateef IC, Ogundipe JA, Mogbeyteren E, Banjo MA. Birth preparedness and complication readiness among women attending three levels of health facilities in Ife Central Loca Government, Nigeria. J Community Med Primary Health Care 2011;23(1):41-54. http://www.ajol.info/ index.php/jcmphc/article/view/84664/74652

6. Doctor HV, Findley SE, Cometto G, Afenyadu GY. Awareness of critical danger signs of pregnancy and delivery, and preparations for delivery, and utilization of skilled birth attendants in Nigeria. J Health Care Poor Underserved 2013 24(1):152-170. http://dx.doi.org/10.1353/hpu.2013.0032]

7. Etsako Central LGA. Projected population and work plan for routine immunization, 2011. Department of Primary Health Care, Etsako Central LGA, Fugar.

8. Hailu M, Gebremariam A, Alemseged F, Deribe K. Birth preparedness and complication readiness among pregnant women in Southern Ethiopia. PLoS ONE 2011;6(6):e21432. http://dx.doi.org/10.1371/ journal.pone.0021432

9. Kabakyenga JK, Östergren P, Turyakira E, Pettersson KO. Knowledge of obstetric danger signs and Kabakyenga JK, Ostergren P, Turyakira E, Pettersson KO. Knowledge of obstetric danger signs and
birth preparedness practices among women in rural Uganda. Reprod Health 2011;8(1):33. http://dx.doi. birth preparedness practices amo

10. Urassa DP, Pembe AB, Mganga F. Birth preparedness and complication readiness among women in Mpwapwa District Tanzania. Tanzan J Health Res 2012;14(1):42-47. http://dx.doi.org/10.4314/thrb.v14i1. 11. The World Bank. Successful Approaches to Improving Maternal Health Outcomes. http://go.worldbank org/0K8ELL1EU0 (accessed 26 April 2015).

12. Obi AI, Abe E, Okojie OH. Male and community involvement in birth preparedness and complication readiness in Benin City, Southern Nigeria. IOSR J Dental Med Sci 2013;10(6):27-32.

13. Adeleye OA, Chiwuzie J. 'He does his own and walks away': Perception about male attitudes and practices regarding safe motherhood in Ekiadolor, Southern Nigeria. Afr J Reprod Health 2007;11(1):76-89.

14. Iliyasu Z, Abubakar IS, Galadanci HS, Aliyu MH. Birth preparedness, complication readiness and fathers participation in maternity care in a northern Nigerian community. Afr J Reprod Health 2010;14(1):21-32.

15. Towards $4+5$ Research Programme Consortium. Improving birth outcomes in poor rura communities: The role of women's groups in Nepal, Bangladesh and India. Towards $4+5$ Briefing Paper 5, April 2010. http://r4d.dfid.uk/Output/186923/Default.aspx (accesssed 26 April 2015). 